\title{
Comparative Study between Traditional Approach and Physico-Chemical Approach in Acid Base Disorders Interpretation in Critically Ill Patients
}

\author{
Atef Redwan ${ }^{1}$, Rainer Gatz ${ }^{2}$, Naglaa Hassan ${ }^{3}$, Heba Matter ${ }^{1}$, Adel Hammodi ${ }^{3}$, Adel Attia ${ }^{4}$ \\ ${ }^{1}$ Department of Critical Care, Faculty of Medicine, Zagazig University, Zagazig, Egypt \\ ${ }^{2}$ Department of Anasthesia ICU, Herlev Hospital, Copenhagen, Denmark \\ ${ }^{3}$ Department of Critical Care, King Fahad Specialist Hospital, Dammam, KSA \\ ${ }^{4}$ Department of Pulmonology, Faculty of Medicine, Zagazig University, Zagazig, Egypt
}

Email: adelattia68@yahoo.com

Received August 4, 2013; revised September 20, 2013; accepted October 6, 2013

Copyright (C) 2013 Atef Redwan et al. This is an open access article distributed under the Creative Commons Attribution License, which permits unrestricted use, distribution, and reproduction in any medium, provided the original work is properly cited.

\begin{abstract}
Objective: The traditional approach for acid base interpretation is based on Handerson-Hasselbalch formula and includes Base Excess (BE), bicarbonate $\left(\mathrm{HCO}_{3}\right)$, albumin corrected anion gap. The Physicochemical approach is centered on the Carbon Dioxide tension $\left(\mathrm{PCO}_{2}\right)$, the strong ion difference (SID), strong ion gap (SIG) = SID apparent-SID effective and totally weak acids (Atot). The study aims to compare between the traditional approach and the physicochemical approach in acid base disorder interpretation. Design: Prospective observational study in an adult Intensive Care Unit (ICU) recruiting six hundred and sixty one patients. Methods: Arterial blood samples were analyzed to measure $\mathrm{pH}$, $\mathrm{PaCO}_{2}$ sodium, potassium, chloride and lactate. Venous blood samples were analyzed to measure ionized calcium, magnesium, phosphorous and albumin. These samples were interpreted by both techniques. Results: Normal $\mathrm{HCO}_{3}$ and BE were detected by traditional approach in 49 cases of which SIG acidosis was detected in 22 cases $(46 \%)$ and Hyperchloremic acidosis was detected in 29 cases $(60 \%)$ by physicochemical method. SIG was elevated in 72 cases $(58 \%)$ of 124 cases with high anion gap acidosis. SIDeff and BE were strongly correlated, $r=0.8, p<0.0001$, while SIG and Albumin corrected Anion Gap (ALAG) were moderately correlated $r=0.56, p<0.0001$. Conclusion: Both approaches are important for interpretation of the acid base status. Traditional approach identifies the diagnostic description without many calculations and detects body compensatory response to acid base disorders. Physicochemical approach is essential to identify the exact causation and the severity of the acid base disorders.
\end{abstract}

Keywords: Anion Gap; Base Excess; Bicarbonate; Strong Ion Gap; Total Weak Acids

\section{Introduction}

Acid base disorders are common in critically ill patients and cause high morbidity and mortality $[1,2]$. It is important to appropriately diagnose acid base disorders to appropriately manage them. There are different approaches to diagnose acid base disorders. The most commonly practiced approach is based on Henderson-Hasselbalch method and include Base deficit (BE) and bicarbonate $\left(\mathrm{HCO}_{3}\right)$ as the metabolic variables and enhanced by the Anion Gap (AG). Based on this approach, the $\mathrm{HCO}_{3}$ changes in plasma reflect the changes in nonvolatile acids as lactic and keto-acids while the changes in $\mathrm{PCO}_{2}$ directly affect the $\mathrm{pH}$ [3]. As $\mathrm{HCO}_{3}$ changes with the change in $\mathrm{PCO}_{2}$ according to the carbonic acid equilibrium reaction, $\mathrm{HCO}_{3}$ can't represent the metabolic acid base disorders unless the effect of $\mathrm{PCO}_{2}$ is considered [2]. All acid-base approaches agree in their analysis of the respiratory component of acid-base equilibrium, referring to the same formulation of the reaction

$$
\mathrm{CO}_{2}+\mathrm{H}_{2} \mathrm{O} \Leftrightarrow \mathrm{H}^{+}+\mathrm{HCO}_{3}^{-},
$$

in the format known as the Henderson-Hasselbalch equation [4]. They differ in how they analyze the "metabolic" side of the acid-base equilibrium. The physicochemical approach was studied first by Donald van Slyke et al. [5]. Followed by Peter Stewart who introduced the six formulae and four mass equilibrium calculations for chemical reactions [6], 
1) $\mathrm{CO}_{2}+\mathrm{H}_{2} \mathrm{O} \rightarrow \mathrm{H}^{+}+\mathrm{HCO}_{3}^{-}$

2) $\mathrm{HCO}_{3}^{-} \rightarrow \mathrm{H}^{+}+\mathrm{CO}_{3}^{-}$

3) $\mathrm{H}_{2} \mathrm{O} \rightarrow \mathrm{H}^{+}+\mathrm{OH}^{-}$

4) The plasma weak acids, lumped together as one single entity: $\mathrm{HA} \rightarrow \mathrm{H}^{+}+\mathrm{A}^{-}$

Stewart's six simultaneous equations [7]

1) Dissociation equilibrium for water

$$
\left[\mathrm{H}^{+}\right] *\left[\mathrm{OH}^{-}\right]=\mathrm{Kw}
$$

2) Dissociation equilibrium for the weak acids

$$
\left[\mathrm{H}^{+}\right] *\left[\mathrm{~A}^{-}\right]=\mathrm{KA} *[\mathrm{HA}]
$$

3) Mass conservation for the total amount of weak acids

$$
[\mathrm{HA}]+\left[\mathrm{A}^{-}\right]=[\text {Atot }]
$$

4) Dissociation equilibrium for carbonic acid to bicarbonate

$$
\left[\mathrm{H}^{+}\right] *\left[\mathrm{HCO}_{3}^{-}\right]=\mathrm{Kc} * \mathrm{PCO}_{2}
$$

5) Dissociation equilibrium for bicarbonate to carbonate

$$
\left[\mathrm{H}^{+}\right] *\left[\mathrm{CO}_{3}^{2-}\right]=\mathrm{K}_{3} *\left[\mathrm{HCO}_{3}^{-}\right]
$$

6) Requirement for electrical neutrality:

$$
\begin{aligned}
& {[\mathrm{SID}]+\left[\mathrm{H}^{+}\right]-\left[\mathrm{HCO}_{3}^{-}\right]-\left[\mathrm{A}^{-}\right]-2 *\left[\mathrm{CO}_{3}^{2-}\right]-\left[\mathrm{OH}^{-}\right]} \\
& =0
\end{aligned}
$$

Combining these mathematically simple 6 equations leads to one single formula where the only unknown variable is $\left[\mathrm{H}^{+}\right]$, the other variables being completely independent of one another and immutable as long as no external influences change the plasma composition and they are the strong ion difference (SID), the total weak acids (Atot) and the partial pressure of $\mathrm{CO}_{2}\left(\mathrm{PCO}_{2}\right)$.

Substituting from the first five equations into the 6 th:

$$
\begin{aligned}
& {[\mathrm{SID}]+\left[\mathrm{H}^{+}\right]-\mathrm{Kc}^{2} \mathrm{PCO}_{2} /\left[\mathrm{H}^{+}\right]} \\
& -\mathrm{KA} *[\text { Atot }] /\left(\mathrm{KA}+\left[\mathrm{H}^{+}\right]\right)-\mathrm{K}_{3} * \mathrm{Kc}^{2} * \mathrm{PCO}_{2} /\left[\mathrm{H}^{+}\right]^{2} \\
& -\mathrm{Kw}^{\prime} /\left[\mathrm{H}^{+}\right]=0
\end{aligned}
$$

Stewart introduced the physicochemical approach which was refined later by Alfaro, Figge and Fencle $[8,9]$.

\section{Subjects and Methods}

Design and Setting: This was a prospective observational study done in medical and surgical Adult Intensive Care Unit (AICU) at a tertiary hospital in Dammam-KSA. Patients admitted to the ICU during the period from
January 2010-December 2011 were included in the study. The study was approved by the Institutional Research Board (IRB). Informed consent was waived as the laboratory tests and data collected anonymously in this study were part of routine clinical practice.

Measurements: Arterial blood and venous blood samples were drawn for blood gases and a serum biochemical panel. Demographic data (age, gender) were recorded. Blood gases, electrolytes and lactate were immediately analyzed to measure $\mathrm{pH}$ and $\mathrm{PaCO}_{2}$ and electrolytes using (Biomed ABL 700 Radiometer Copenhagen). Venous blood sample was analyzed to measure ionized calcium (Ca), Magnesium $(\mathrm{Mg}$ ) inorganic phosphate (Pi) albumin (alb) and lactate using (colorimetric technique, Roche Diagnostics).

Calculated Variables: Bicarbonate and SBE were calculated using the Henderson-Hasselbalch diagnostics [2]. The anion gap (AG) was calculated by the standard formula,

$$
\mathrm{AG}=\left[\mathrm{Na}^{+}\right]+\left[\mathrm{K}^{+}\right]-\left[\mathrm{Cl}^{-}\right]+\left[\mathrm{HCO}_{3}^{-}\right]
$$

[10] and corrected for albumin [11] with an elevated AG defined as greater than $16 \mathrm{mEq} / \mathrm{L}$. ALAG (albumin corrected anion gap) $=$ AG calculated +0.25 (42-albumin $\mathrm{g} / \mathrm{l}$ ). To diagnose combined normal and high anion gap acidosis or hidden metabolic alkalosis with metabolic acidosis, bicarbonate gap was calculated.

Bicarbonate $\left(\mathrm{HCO}_{3}\right)$ gap $=\mathrm{NaCl}-36[11,12]$. Physiochemical analysis was performed using the Stewart equations.

\subsection{Statistical Analysis}

Statistical analysis was done by using SPSS software. Acid base diagnoses were compared from both the traditional approach and the physiochemical approach using cross tabulation and chi square test.

Diagnostic categories were defined as follows (normal diagnosis was considered a separate category if encountered).

\subsubsection{Traditional Approach Categories: [13,14] Simple Categories}

1) Metabolic acidosis $\downarrow \mathrm{pH} \downarrow \mathrm{HCO}_{3} \downarrow \mathrm{PCO}_{2}$. Expected $\mathrm{PCO}_{2}=1.5 * \mathrm{HCO}_{3}+8$

2) Metabolic alkalosis $\uparrow \mathrm{pH} \uparrow \mathrm{HCO}_{3} \uparrow \mathrm{PCO}_{2}$. Expected $\mathrm{PCO}_{2}=0.7 * \mathrm{HCO}_{3}+20$

3) Respiratory acidosis $\downarrow \mathrm{pH} \uparrow \mathrm{HCO}_{3} \uparrow \mathrm{PCO}_{2}$. Expected $\mathrm{HCO}_{3}=0.1-0.3 * \Delta \mathrm{PCO}_{2}$

4) Respiratory alkalosis $\uparrow \mathrm{pH} \downarrow \mathrm{HCO}_{3} \downarrow \mathrm{PCO}_{2}$. Expected $\mathrm{HCO}_{3}=0.2-0.5 * \Delta \mathrm{PCO}_{2}$

\subsubsection{Mixed Categories}

1) If the secondary compensation out of expected range. 
2) Using the bicarbonate (delta gap) gap $[15,16] . *$ If delta gap $>+6-$ Mixed high anion gap and normal anion gap acidosis.

* If delta gap -6 - +6-Simple anion gap acidosis.

* If delta gap <-6-Mixed high anion gap acidosis and metabolic alkalosis.

\subsubsection{Physicochemical Approach Categories [17-19]}

Effective SID (with normal value of $35 \pm 5 \mathrm{mEq} / \mathrm{L}$ ) and SIG (with normal value of \pm 5 ) was calculated as follows: (17)

- $\quad$ SID effective $=\mathrm{HCO}_{3}+$ albumin + Pi. Albumin and Pi $(\mathrm{mmol} / \mathrm{L})$ were calculated from the measured albumin $(\mathrm{g} / \mathrm{L}), \mathrm{Pi}(\mathrm{mmol} / \mathrm{L})$, and $\mathrm{pH}$

- Albumin $^{-}=$albumin $*(0.123 * \mathrm{pH}-0.631)$.

- $\mathrm{Pi}^{-}=\mathrm{Pi} *(0.309 * \mathrm{pH}-0.469)$.

Apparent SID was calculated:

- $\quad$ SID apparent $=\mathrm{Na}+\mathrm{K}+\mathrm{Ca} 2+\mathrm{Mg} 2-\mathrm{Cl}$.

Strong ion gap (SIG) is composed of strong anions other than $\mathrm{Cl}^{-}$(lactate, ketoacids and other organic anions, sulfate) and was calculated as follows:

SID apparent - SID effective.

\section{Results}

Six hundred and sixty one patients were included in the study medical and surgical cases, their epidemiologic, clinical, and outcome variables are shown in Table 1.

Measured and calculated acid base variables in normal reference lab values and in critically ill patients are shown in Table 2. Analyzing the 661 cases with traditional method resulted in, high anion gap acidosis was recorded in 125 cases $(18.9 \%)$ cases, mixed metabolic acidosis and respiratory acidosis in 190 episodes (28.9\%), mixed metabolic alkalosis and respiratory acidosis in 86 cases $(13 \%)$. Respiratory acidosis in 108 episodes $(16.3 \%)$, respiratory alkalosis in 33 cases (4.8\%) cases and mixed metabolic acidosis and respiratory alkalosis in 22 cases (3.3\%). Chloride sensitive metabolic alkalosis was detected in 16 cases $(2.4 \%)$ of all cases, mixed metabolic alkalosis and respiratory alkalosis in 31 cases $(4.7 \%)$ (Figure 1). On the other hand, applying physicochemical method, Hypoalbuminemic metabolic alkalosis was recorded in 513 cases $(77.8 \%)$ of all cases. SIG acidosis was recorded in $258(39 \%)$ cases, while respiratory acidosis was found in 335 cases (51\%) of all cases, whereas respiratory alkalosis in 163 cases $(25 \%)$ of all study population cases. SIG and ALAG were elevated in 258 cases $(39.1 \%)$ and in 125 cases $(19 \%)$ of all cases respectively. Hyperlactatemia (lactate level $>2.2$ ) was detected in 105 cases $(16 \%)$, severe hyperlactatemia (lactate level $>4.5$ ) in 26 cases (4\%). Hypoalbuminemia was identified in 513 cases $(77.8 \%)$ off all study population. Normal $\mathrm{HCO}_{3}$ and $\mathrm{BE}$ were noticed in 49 cases of which SIG acidosis was detected in 22 cases $(46 \%)$ so physico-
Table 1. Epidemiological and clinical variables.

\begin{tabular}{cc}
\hline Total cases & $\mathbf{6 6 1}$ \\
\hline Gender male & $\mathbf{5 9 \%}$ \\
Female & $\mathbf{4 1 \%}$ \\
Medical & $\mathbf{9 3 \%}$ \\
Surgical & $\mathbf{7 \%}$ \\
Invasive ventilation & $\mathbf{4 8 \%}$ \\
BiPAP & $\mathbf{4 . 2 \%}$ \\
Hepatic failure & $\mathbf{1 9 \%}$ \\
Cardiac failure & $5 \%$ \\
Renal failure & $\mathbf{2 0 \%}$ \\
COPD & $35 \%$ \\
OTHERS & $\mathbf{1 4 \%}$ \\
\hline
\end{tabular}

BiPAP: bilevel positive airway pressure.

Table 2. Measured and calculated variables with the reference means of the measured values.

\begin{tabular}{|c|c|c|}
\hline $\begin{array}{l}\text { Variable } \\
\text { reference }\end{array}$ & $\begin{array}{c}\text { Value } \\
(\text { mean } \pm \text { SD) }\end{array}$ & $\begin{array}{c}\text { Patients value } \\
\text { (mean } \pm \text { SD) }\end{array}$ \\
\hline Sodium $\{\mathrm{Na}\} \mathrm{mmol} / \mathrm{L}$ & $141 \pm 2$ & $138 \pm 6$ \\
\hline Potasium $\{\mathrm{K}\} \mathrm{mmol} / \mathrm{L}$ & $4.3 \pm 0.5$ & $4 \pm 0.7$ \\
\hline Calcium $(\mathrm{Ca}) \mathrm{mmol} / \mathrm{L}$ & $2.4 \pm 0.1$ & $1.4 \pm 0.4$ \\
\hline Magnesium mmol/L & $0.8 \pm 0.03$ & $0.9 \pm 0.2$ \\
\hline Chloride $\{\mathrm{Cl}\} \mathrm{mmol} / \mathrm{L}$ & $103 \pm 3$ & $105 \pm 6$ \\
\hline Phosphorus (Pi) mmol/L & $1.1 \pm 0.2$ & $1.1 \pm 0.4$ \\
\hline Albumin (alb) g/dl & $42 \pm 4$ & $28 \pm 7$ \\
\hline $\mathrm{pH}$ & $7.4 \pm 0.0$ & $7.3 \pm 0.1$ \\
\hline $\mathrm{PCO}_{2} \mathrm{mmHg}$ & $40 \pm 3$ & $45 \pm 15$ \\
\hline Lactate $(\mathrm{L}) \mathrm{mmol} / \mathrm{L}$ & $1.2 \pm 0.5$ & $1.8 \pm 1.7$ \\
\hline \multicolumn{3}{|c|}{ Derived variables, $\mathrm{mmol} / \mathrm{L}$ (patients) } \\
\hline $\mathrm{HCO}_{3}$ & \multicolumn{2}{|c|}{$24 \pm 8$} \\
\hline AGadj & \multicolumn{2}{|c|}{$15 \pm 5$} \\
\hline $\mathrm{BE}$ & \multicolumn{2}{|c|}{$-1.3 \pm 9$} \\
\hline SIDeff & \multicolumn{2}{|c|}{$33 \pm 9$} \\
\hline SID app & \multicolumn{2}{|c|}{$41 \pm 7.6$} \\
\hline SIG & \multicolumn{2}{|c|}{$8 \pm 6$} \\
\hline $\mathrm{HCO}_{3}$ gap & \multicolumn{2}{|c|}{$-3 \pm 7$} \\
\hline
\end{tabular}

chemical method was able to diagnose metabolic acidosis in cases interpreted as normal by the traditional method. On the other side, SIG was elevated in only 72 episodes $(58 \%)$ of 124 cases with high anion gap acidosis. Hyperchloremic acidosis was detected in $29(60 \%)$ of the 48 cases with normal $\mathrm{HCO}_{3}$ and $\mathrm{BE}$ (Table 3).

In addition, SIG was normal in 337 episodes of which 100 cases $(29.7 \%)$ discovered with mixed metabolic acidosis and respiratory acidosis and another 45 cases 


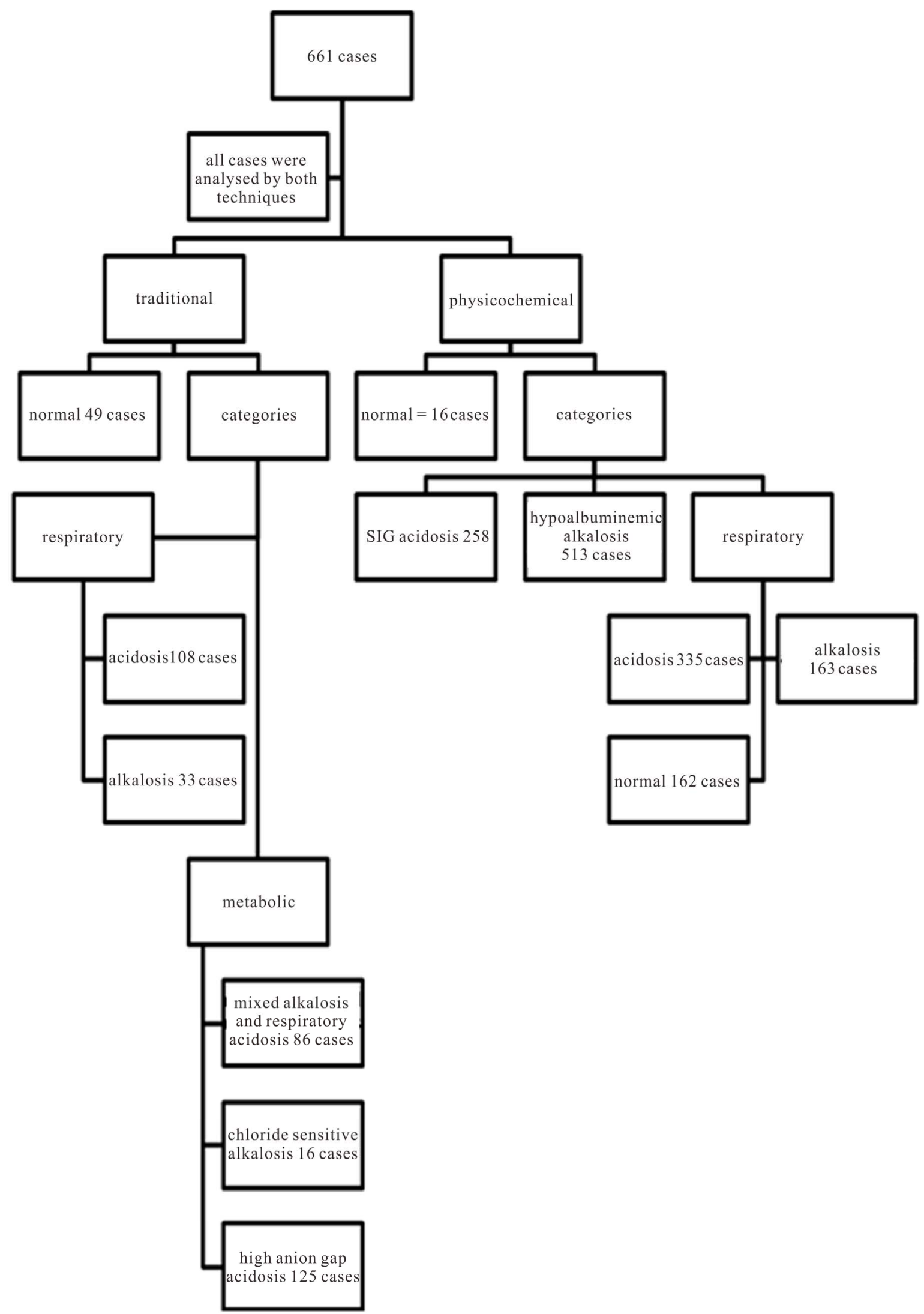

Figure 1. Schematic distribution of the main results of both techniques. 
(13.4\%) with High anion gap metabolic acidosis (Table 3). Hypoalbuminemic metabolic alkalosis was recorded in 39 episodes $(80 \%)$ of 49 cases were reported to be normal by traditional method. SIDeff and BE were strongly correlated $\mathrm{r}=0.8, \mathrm{p}<0.0001$, while SIG and ALAG were moderately correlated $r=0.56, p<0.0001$ (Figures 2 and 3). There is slight agreement between both techniques where kappa in cases of metabolic acidosis was $(\mathrm{k}=0.087)$ and in metabolic alkalosis $(\mathrm{k}=-0.57)$.

\section{Discussion}

The main findings of the study, in the 49 cases with normal $\mathrm{HCO}_{3}, \mathrm{BE}$, and ALAG, The physicochemical approach can identify respiratory acidosis in $(22 \%)$ of the cases, respiratory alkalosis in $(10 \%)$, SIG acidosis in (46\%), Hyperchloremic acidosis in (60\%), Hypoalbuminemic metabolic alkalosis $(80 \%)$, and hypophosphatemia (10\%). The hyperchloremic acidosis cases dis-

Table 3. Classification of patients by traditional approach and physiochemical approach.

Normal value of $\mathrm{HCO}_{3}, \mathrm{PCO}_{2}$, BE, ALAG (n: 49)

Respiratory acidosis 7 (4.3\%)

Respiratory alkalosis $9(5.5 \%)$

Metabolic acidosis and respiratory alkalosis $3(1.8 \%)$

Metabolic alkalosis and respiratory acidosis $26(16 \%)$

Normal $\mathrm{pCO}_{2} 46(28 \%)$

Other 72

Metabolic alkalosis and respiratory alkalosis 7 (4.7\%)

Metabolic alkalosis and respiratory acidosis 14 (9.5\%)

Chloride sensitive metabolic alkalosis 4 (2.7\%)

Chloride sensitive metabolic alkalosis 7 (3.1\%)

High anion gap metabolic acidosis 13 (5.8\%)

Metabolic acidosis and respiratory acidosis 79 (35.4\%)

High anion gap acidosis 92 (7.2\%)

Metabolic acidosis and respiratory acidosis 144 (26.9\%)

Metabolic alkalosis and respiratory acidosis 75 (14\%)

High anion gap metabolic acidosis 45 (13.4\%)

Metabolic acidosis and respiratory acidosis 100 (29.7\%)
Physiochemical approach

\author{
Respiratory acidosis 11 (22\%) \\ Respiratory alkalosis 5 (10\%) \\ Normal $\mathrm{PCO}_{2} 33$ (68\%) \\ Hypoalbuminic alkalosis $39(80 \%)$ \\ Normal albumin 10 (20\%) \\ Hyperphosphatemic acidosis 2 (4\%) \\ Hypophosphatemia 5 (20\%) \\ Normal Pi 42 (86\%) \\ Hyperchloremic acidosis 29 (60\%) \\ Hypochloremic alkalosis 4 (8\%) \\ Normal chloride 16 (32\%) \\ SIG acidosis $22(46 \%)$ \\ Normal SIG 27 (54\%) \\ Lactic acidosis 7 (14\%) \\ Normal lactate $42(86 \%)$
}

Normal value of $\mathrm{PCO}_{2}$ (n: 163)

Normal value of albumin (n: 148)

Normal value of chloride (n: 223)

Normal value of Pi (n: 535)

Normal value of SIG (n: 337) 


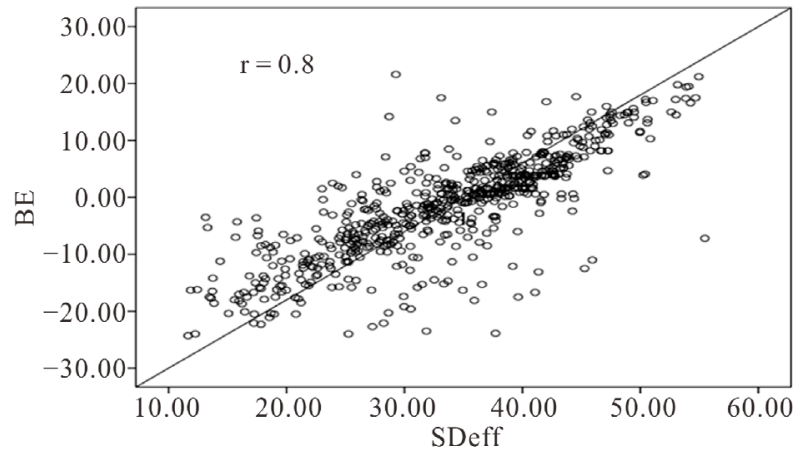

Figure 2. Correlation between effective strong ion difference (SIDeff) and base excess (BE).

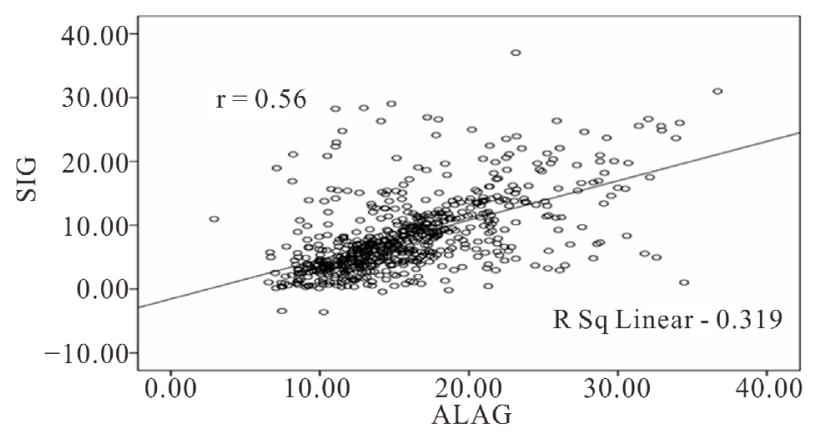

Figure 3. Correlation between SIG (strong ion gap) and ALAG (Albumin corrected anion gap).

covered by physicochemical approach with normal $\mathrm{HCO}_{3}$ were revised because according to the stoichiometry of these anions namely $\mathrm{Cl}$ and $\mathrm{HCO}_{3}$, it is hard to find normal bicarbonate with high chloride. These cases were found to be either combined with alkalosis or COPD patients. The total respiratory disorders were discovered by physicochemical approach significantly more than the traditional approach. This can be explained by the basic idea of the physicochemical approach of segregating the independent factors that affect the $\mathrm{pH}$ which results in loss of the ability to appreciate the deviation from expected compensation which is well considered by the traditional technique. Although the respiratory variable $\left(\mathrm{PCO}_{2}\right)$ is the same in both the traditional and physicochemical interpretation approach, we found high percentage of respiratory disorders was identified by the traditional approach in cases appeared as normal $\mathrm{PCO}_{2}$ by the physicochemical approach. Actually, this percentage represents compensatory respiratory changes in cases of metabolic disorders. For the same reason, the traditional approach could diagnose Respiratory acidosis 7 cases $(4.3 \%)$, respiratory alkalosis 9 cases $(5.5 \%)$, metabolic acidosis and respiratory alkalosis 3 cases $(1.8 \%)$, metabolic alkalosis and respiratory acidosis 26 cases (16\%) from 163 cases diagnosed as normal $\mathrm{PaCO}_{2}$ by the physicochemical approach. High anion gap acidosis
(13\%) was detected in cases of normal SIG. there was also moderate correlation between the ALAG and SIG ( $\mathrm{r}$ $=0.51$ ) where other studies found higher correlation between them [13,14,24]. Fencl et al. [13] had already demonstrated that $\mathrm{BE}$ fails as a measure of metabolic acidosis when there is a change in the plasma concentration of the non-bicarbonate buffers, an almost universal disorder in critically ill patients. Kellum $[20,22,23]$ considered that both methods yield virtually identical results, despite a different conceptual approach to underlying mechanisms. In contrary to our study which showed different results mainly in case of metabolic acidosis and respiratory compensation cases. Dubin [14] found that $15 \%$ of their cases were misinterpreted as primary metabolic disorder rather than compensation to the primary respiratory disorder and when adding corrected AG to the traditional model, concluded that both methods are equivalent in diagnosing acid-base disorders. Dubin et al. [14] also found that the Stewart approach could identify metabolic acidosis in $14 \%$ of patients with normal $\mathrm{HCO}_{3}$ and $\mathrm{BE}$ and in $1 \%$ only if the anion gap was included with $\mathrm{HCO}_{3}$ and $\mathrm{BE}$ during interpretation. Dubin also [14] identified that, the Stewart approach failed to diagnose metabolic acid base disorders in 3\% of cases with abnormal $\mathrm{HCO}_{3}, \mathrm{BE}$ and ALAG. Meanwhile in our study this finding was raised to reach about $21 \%$ of total cases either high anion gap or mixed metabolic and respiratory acidosis which couldn't be detected by stewart approach (SIG was normal). Bonaetti et al. [23] decided to use the absolute value of the anions (chloride, lactate and unmeasured anions), instead of classifying the type of metabolic acidosis according to the predominant anion and concluded that physicochemical evaluation, compared to the traditional evaluation, results in identification of more patients with major acid-base disturbances. In the present study results showed that both methods has ability to discover metabolic disorder where less calculation and significantly more detection in the traditional side augmented by ALAG. As we measure the agreement between both techniques, it results in slight agreement where kappa in cases of acidosis was $(\mathrm{k}=0.087)$. This outcome points to the area of the results that can be diagnosed solely by each technique. This means that both techniques can be combined to produce a potent tool of diagnosis in acid base disorders. Similar conclusion was stated by Kellum "Both quantitative and traditional approaches can be easily combined to result in a powerful tool for bedside acid-base analysis" [25].

\section{Conclusion}

Combining both approaches is important to have a precise view of the acid base status. As the traditional approach defines the diagnostic description easily, espe- 
cially regarding the body compensatory response to metabolic acid base disorders while the physicochemical approach is important to define the causation and severity of acid base disorders.

\section{REFERENCES}

[1] "Disorders," Clinical Journal of the American Society of Nephrology, Vol. 4, No. 7, 2009, p. 1267.

[2] K. J. Gunnerson and J. A. Kellum, “Acid-Base and Electrolyte Analysis in Critically Ill Patients: Are We Ready for the New Millennium?" Current Opinion in Critical Care, Vol. 9, No. 6, 2003, pp. 468-473. http://dx.doi.org/10.1097/00075198-200312000-00002

[3] A. A. Sirker, A. Rhodes, R. M. Grounds and E. D. Bennett, "Acid-Base Physiology: The 'Traditional' and the 'Modern' Approaches,” Anesthesia, Vol. 57, No. 4, 2002, pp. 348-356.

http://dx.doi.org/10.1046/j.0003-2409.2001.02447.x

[4] O. Siggard-Andersen, P. D. Wimberly, N. Fogh-Andersen and I. H. Gøthgen, "Measured and Derived Quantities with Modern pH and Blood Gas Equipment: Calculation Algorithms with 54 Equations," Scandinavian Journal of Clinical \& Laboratory Investigation, Vol. 48, Suppl. 189, 1988, pp. 7-15.

[5] D. D. Van Slyke, H. Wu and F. C. McLean, "Studies of Gas and Electrolyte Equilibria in the Blood. V. Factors Controlling the Electrolyte and Water Distribution in the Blood," Journal of Biological Chemistry, Vol. 56, 1923, pp. 765-849.

[6] P. A. Stewart, "Modern Quantitative Acid-Base Chemistry," Canadian Journal of Physiology and Pharmacology, Vol. 61, No. 12, 1983, pp. 1441-1461. http://dx.doi.org/10.1139/y83-207

[7] P. A. Stewart, "Independent and Dependent Variables of Acid Base Control," Respiration Physiology, Vol. 33, No. 1, 1978, pp. 9-26. http://dx.doi.org/10.1016/0034-5687(78)90079-8

[8] J. Figge, T. Mydosh and V. Fencl, "Serum Proteins and Acid-Base Equilibrium: A Follow-Up," Journal of Laboratory and Clinical Medicine, Vol. 120, No. 5, 1992, pp. 713-719.

[9] J. Figge, T. H. Rossing and V. Fencl, "The Role of Serum Proteins in Acid-Based Equilibria," Journal of Laboratory and Clinical Medicine, Vol. 117, No. 6, 1991, pp. 453-467.

[10] P. D. Constable and H. R. Stampfli, "Experimental Determination of Net Protein Change and Atot and $\mathrm{Ka}$ of Nonvolatile Buffers in Human Plasma," Journal of Applied Physiology, Vol. 95, 2003, p. 620.

[11] O. Siggaard-Andersen, "The Acid-Base Status of the Blood," 4th Edition, Munksgaard, Copenhagen, 1976.

[12] J. W. Severinghaus, "Siggaard-Andersen and the Great Trans-Atlantic Acid-Base Debate," Scandinavian Journal of Clinical \& Laboratory Investigation, Vol. 53, Suppl.
214, 1993, pp. 99-104.

[13] M. Moviat, F. van Haren and H. van der Hoeven, "Conventional or Physicochemical Approach in Intensive Care Unit Patients with Metabolic Acidosis," Critical Care, Vol. 7, 2003, pp. R41-R45. http://dx.doi.org/10.1186/cc2184

[14] A. Dubin, M. M. Menises, F. D. Masevicius, M. C. Moseinco, D. O. Kutscherauer, E. Ventrice, E. Laffaire and E. Estenssoro, "Comparison of Three Different Methods of Evaluation of Metabolic Acid-Base Disorders," Critical Care Medicine, Vol. 35, No. 5, 2007, pp. 1264-1270. http://dx.doi.org/10.1097/01.CCM.0000259536.11943.90

[15] R. G. Narins, "Maxwell and Kleeman's Clinical Disorders of Fluid and Electrolyte Metabolism," 5th Edition, McGraw-Hill, New York, 1994.

[16] K. Wrenn, "The Delta (Delta) Gap: An Approach to Mixed Acid-Base Disorders," Annals of Emergency Medicine, Vol. 19, No. 11, 1990, pp. 1310-1313. http://dx.doi.org/10.1016/S0196-0644(05)82292-9

[17] J. Figge, A. Jabor, A. Kazda, et al., "Anion Gap and Hypoproteinemia," Critical Care Medicine, Vol. 26, No. 11, 1998, pp. 1807-1810. http://dx.doi.org/10.1097/00003246-199811000-00019

[18] D. A. Story, H. Morimatsu and R. Bellomo, "Strong Ions Weak Acids and Base Excess: A Simplified Fencl-Stewart Approach to Clinical Acid-Base Disorders," British Journal of Anaesthesia, Vol. 92, No. 1, 2004, pp. 54-60. http://dx.doi.org/10.1093/bja/aeh018

[19] T. D. DuBose Jr., “Acidosis and Alkalosis," In: D. L. Kasper, E. Braunwald, et al., Eds, Harrison's Principles of Internal Medicine, 16th Edition, McGraw-Hill, New York, 2005, pp. 263-271.

[20] J. A. Kellum, "Determinants of Blood $\mathrm{pH}$ in Health and Disease," Critical Care, Vol. 4, 2000, pp. 6-14. http://dx.doi.org/10.1186/cc644

[21] V. Fencl, A. Jabor, A. Kazda, et al., "Diagnosis of Metabolic Acid-Base Disturbances in Critically Ill Patients," American Journal of Respiratory and Critical Care Medicine, Vol. 162, No. 6, 2000, pp. 2246-2251. http://dx.doi.org/10.1164/ajrccm.162.6.9904099

[22] J. A. Kellum, "Disorders of Acidbasebalance," Critical Care Medicine, Vol. 35, No. 11, 2007, pp. 2630-2636. http://dx.doi.org/10.1097/01.CCM.0000286399.21008.64

[23] M. M. Boniatti, P. C. Cardoso, R. K. Castilho, S. R. Vieira, G. Friedman, S. P. Ribeiro and L. Fialkow, "Prognostic Value of Unmeasured Anions in Critically Ill Patients," Intensive Care Medicine, Suppl. 1, 2008, p. S24.

[24] J. A. Kellum, "Strong Ion Gap: A Methodology for Exploring Unexplained Anions," Journal of Critical Care, Vol. 10, No. 2, 1995, pp. 51-55.

http://dx.doi.org/10.1016/0883-9441(95)90016-0

[25] J. A. Kellum, "Disorders of Acid-Base Balance," Critical Care Medicine, Vol. 35, No. 11, 2007, pp. 2630-2636. http://dx.doi.org/10.1097/01.CCM.0000286399.21008.64 